\title{
RANCANG BANGUN PENGOPERASIAN LAMPU MENGGUNAKAN SINYAL ANALOG SMARTPHONE BERBASIS MIKROKONTROLLER
}

\author{
Zainal Abidin ${ }^{1)}$, Tijaniyah, S.Kom., MT. ${ }^{2)}$, Moh. Bachrudin, S.T ${ }^{3)}$ \\ Teknik Elektro Sekolah Tinggi Teknologi Nurul Jadid \\ Karanganyar Paiton Probolinggo \\ Email : zainalak12c@gmail.com ${ }^{1)}$ tijaniyah@sttnj.ac.id ${ }^{2)}$, moh.bachrudin@ytljt.com ${ }^{3)}$
}

\begin{abstract}
Abstrak. Umumnya piranti elektonik pada rumah tangga dikendalikan secara manual, contohnya lampu. Lampu adalah piranti elektronik yang berfungsi untuk penerangan sehingga sangat penting untuk kegiatan di dalam rumah setiap harinya. Namun akan terjadi kesulitan untuk menyalakan lampu setiap waktu, secara manual saat seseorang memiliki kesibukan yang lain. Oleh karena itu, perlu adanya alat pengendali yang bisa digunakan secara efisien dari jarak jauh. Berdasarkan pemikiran tersebut, Tujuan dari penelitian ini adalah membuat alat yang dapat digunakan untuk mengendalikan ON/OFF lampu dari jarak jauh menggunakan sinyal analog smartphone android berbasis mikrokontroler. Sistem kendali ini memanfaatkan wifi yang ada dalam Smartphone Android yang terhubung dengan ESP8266. Kemudian sinyal yang masuk akan diproses oleh Arduino Wemos D1 sebagai pusat kendali. Hasil pengujian elektronika pada penelitian ini menyatakan bahwa alat dapat memberi kemudahan untuk pengguna saat ingin menghidupkan atau mematikan lampu. Sistem kendali lampu ini dapat dikelola secara mandiri untuk masing-masing lampu pada setiap ruangan yang dikendalikan oleh pengguna dari Web Browser aplikasi smartphone android yang sudah tersedia.
\end{abstract}

Kata Kunci : Web Browser, IP Address, Android, Mikrokontroler.

\section{PENDAHULUAN}

\subsection{Latar Belakang Masalah}

Pada zaman teknologi ini kebutuhan akan penggunaan dan peningkatan efisiensi waktu di masyarakat menjadi hal yang sangat diprioritaskan untuk dapat memanajemen waktu secara realtime. Hal ini menjadi sangat penting, guna mendukung peningkatan mobilitas pengguna, salah satunya yaitu implementasi sistem kontrol lampu menggunakan microcontroller dan Web Browser aplikasi Android sebagai pengendalian lampu [1].

Masyarakat selama ini menggunakan saklar guna operasi ON/OFF lampu dengan cara konvensional, kurangnya pengetahuan masyarakat tentang penggunaan saklar yang baik sehingga mengakibatkan masyarakat terkena arus listrik dan seringnya terjadi kebakaran rumah yang dikarenakan reduksi arus listrik pada saklar. Lampu secara konvensional tersebut kurang efektif dan efisien [2].

Sistem pengendali lampu menggunakan mikrokontroler Wemos D1 berbasis smartphone androit sehingga dapat dikendalikan dengan jarak jauh, dan masyarakat dapat lebih mudah mengoperasikan lampu dengan baik dan aman [3].

\subsection{Rumusan Masalah}

Berdasarkan penjelasan pada latar belakang yang telah dikemukakan, maka rumusan masalahnya adalah: 
1. Bagaimana membuat sebuah sistem kontrol ON/OFF pada lampu yang dikendalikan dari sebuah smartphone android dengan memanfaatkan sinyal analog.

\subsection{Batasan Masalah}

Batasan masalah bertujuan untuk membatasi pembahasan dan agar masalah-masalah menjadi lebih terarah. Adapun batasan-batasan tersebut diantaranya:

1. Sistem kendali lampu menggunakan smartphone android dengan memanfaatkan fasilitas sinyal analog.

2. Sistem dirancang baru menggunakan ESP8266 sebagai modul wifi melalui webserver pada jaringan local.

\subsection{Tujuan Penelitian}

Tujuan yang ingin dicapai dari penelitian ini adalah:

1. Menghasilkan suatu project yang dapat dikendalikan dengan smartphone android melalui koneksi sinyal analog.

\subsection{Manfaat Penelitian}

Pembuatan alat ini diharapkan dapat bermanfaat bagi mahasiswa, lembaga pendidikan, dan industri. Adapun manfaat yang diharapkan dari pembuatan tugas akhir ini antara lain:

a Dapat digunakan sebagai pembelajaran dan penambah wawasan tentang alat pengoperasian lampu menggunakan sinyal analog berbasis mikrokontroler, serta sebagai kajian untuk pengembangan selanjutnya.

b Sebagai bentuk kontribusi terhadap STT Nurul Jadid khususnya Teknik Elektro dan pengabdian kepada masyarakat dalam bentuk karya alat yang bermanfaat.

\section{STUDI PUSTAKA}

\subsection{Pengertian sistem}

Sistem adalah suatu kesatuan prosedur atau kumpulan dari komponen-komponen yang memiliki keterkaitan antara satu dan lainnya bekerja bersama-sama sesuai dengan aturan yang diterapkan sehingga terbentuk suatu tujuan yang sama. Dalam sebuah system apabila terjadi salah satu komponen yang tidak bekerja atau rusak maka sistem tidak akan bekerja sesuai dengan yang diinginkan [4].

\subsection{Wifi Modul ESP8266}

Modul ESP8266 adalah mikrokontroler atau (lebih tepatnya) SOC-System On Chip yang memiliki kapabilitas untuk terhubung dengan jaringan WIFI. ESP8266 memiliki firmware yang bisa di program dengan arduino IDE. Selain itu juga terdapat beberapa pin yang berfungsi sebagai GPIO (General Port Input/Output) yang dapat digunakan untuk mengakses sensor atau dihubungkan dengan arduino, sehingga memberikan kemampuan tambahan arduino untuk bisa terhubung ke Wifi [5].

\subsection{Android}

Irawan menyatakan, bahwa android merupakan sebuah sistem operasi yang berbasis linux untuk perangkat portable seperti smartphone dan komputer tablet. Android menyediakan platform terbuka (open source) bagi programmer untuk mengembangkan aplikasi sendiri pada berbagai perangkat dengan sistem android [6].

\subsection{Wemos D1 R2}

Wemos merupakan salah satu modul board yang dapat berfungsi dengan arduino khususnya untuk project yang mengusung konsep IOT. Wemos dapat running stand-alone tanpa perlu dihubungkan dengan mikrokontroler, berbeda dengan modul wifi lain yang masih membutuhkan mikrokontroler sebagai pengrontrol atau otak dari rangkaian tersebut, wemos dapat running standalone karena didalammnya sudah terdapat CPU yang dapat memprogram melalui serial port atau via OTA serta transfer program secara wireless [7].

\subsection{Mikrokontroller Wemos}

Mikrokontroller wemos adalah sebuah mikrokontroller pengembangan berbasis modul mikrokontroller ESP8266. Yang berbeda pada mikrokontroller ini yaitu kemampuannya untuk menyediakan fasilitas konektifitas Wifi dengan mudah serta memory yang digunakan sangat besar yaitu 4 MB [2], [8] .

\subsection{Breadboard}

Breadboard adalah board yang digunakan untuk membuat rangkaian elektronik sementara dengan tujuan uji coba atau prototipe tanpa harus menyolder. Dengan memanfaatkan breadboard, komponen-komponen elektronik yang dipakai tidak akan rusak dan dapat digunakan kembali untuk membuat rangkaian yang lain [9]. 


\subsection{Modul Relay 5 Volt}

Relay adalah sebuah saklar elekronik yang dapat dikendalikan dari rangkaian elektronik lainnya. Relay terdiri dari 3 bagian utama [10], yaitu:

1. Koil : lilitan dari relay.

2. Common : bagian yang tersambung dengan NC (dlm keadaan normal).

3. Kontak : terdiri dari $\mathrm{NC}$ dan $\mathrm{NO}$

\section{METODE PENELITIAN}

\subsection{Rancangan Penelitian}

Penelitian ini merupakan jenis penelitian dan pengembangan atau Research and Development (R\&D). Penelitian dan pengembangan adalah metode penelitian yang digunakan untuk menghasilkan produk tertentu [11].

\subsection{Teknik Pengumpulan Data}

\section{a. Wawancara}

Memaparkan beberapa langkah untuk pelaksanaaan startegi penelitian yakni wawancara, observasi dan studi literatur. Wawancara merupakan pengumpulan data dengan cara mengajukan pertanyaan secara lisan kepada informan, dan pertanyaan itu telah dipersiapkan dengan tuntas beserta instrumennya, atau percakapan dengan maksud tertentu. Proses wawancara dilakukan dengan melakukan tanya jawab kepada pemilik rumah dan tetangga sekitar. Adapun Dalam penelitian ini yang menjadi subjek penelitian adalah pengoperasian lampu yang ber alamatkan Kelurahan karanganyar Kecamatan paiton Probolinggo untuk dapat memanajemen waktu secara realtime. Sumber data utama dari pengoperasian adalah pemilik rumah serta warga sekitar dan tetangga pemilik rumah.

\section{b. Observasi}

Observasi merupakan suatu teknik pengumpulan data dengan pengamatan langsung menggunakan mata tanpa ada alat bantuan untuk keperluan yang dibutuhkan dalam penelitian dengan perencanaan yang sistematik. Mengadakan kunjungan penelitian dan pencatatan secara langsung terhadap sistematika pengoperasian yang di teliti. Peninjauan langsung dilakukan dengan mengadakan survey pada bagian yang berhubungan dengan penelitian serta pendataan yang di perlukan. Observasi yang dilakukan dapat menghasilkan informasi berupa bagaimana keadaan dan pengoperasian pada waktu-waktu tertentu.

\section{c. Studi Literatur}

Studi literatur dengan cara melakukan kajian teori melalui internet (jurnal) dan buku. Buku sebagai referensi dalam konsep dan acuan yang menjelaskan tentang perancangan dan pengembangan sistem untuk memudahkan pembuatan sistem agar mendapatkan hasil yang optimal dan mengevaluasi penelitian yang sudah ada. Sedangkan jurnal sebagai acuan dan mempelajari penelitian yag akan dikembangkan sebelumnya yakni sistem pengoperasian lampu rumah mengunakan android dengan mempertimbangkan penelitian tersebut untuk mengembangkan penelitian yang sudah ada sebelumnya agar mendapatkan hasil yang lebih bermanfaat dan lebih baik.

\subsection{Desain Perangkat Keras Alat Kendali Lampu Dengan Wifi}

Alat dan bahan yang digunakan dalam penelitian, secara umum didesain seperti diagram blok pada Gambar 1. Diagram Blok Desain Alat berikut.

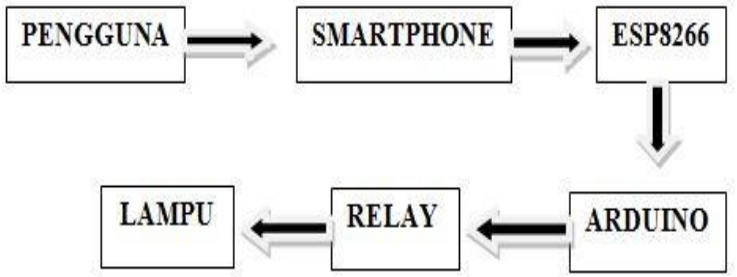

Gambar 1. Diagram Blok Desain Alat Pengoperasian Lampu Dengan Esp8266 Melalui Web Browser Aplikasi Android Berbasis Mikrokontroler

\subsection{FlowChart Alat Kendali Lampu}

Flowchart cara kerja alat kendali lampu dengan wifi melalui aplikasi android berbasis mikrokontroler ditampilkan pada Gambar 2. Flowchart kendali lampu android berikut. 


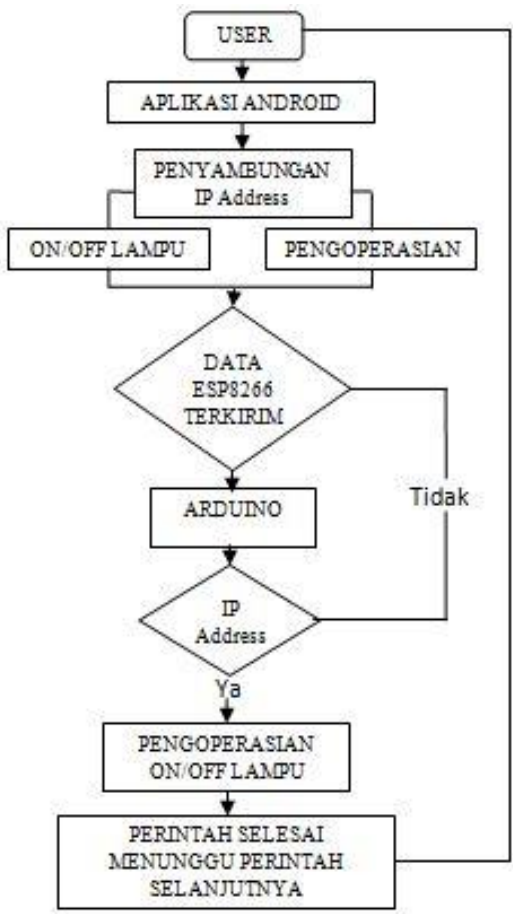

Gambar 2. Flowchart Rancang Bangun Kontrol Lampu Android

\subsection{Pembuatan Alat}

Pembuatan alat operasi lampu dengan ESP8266 melalui Web Browser aplikasi android:

a. Pembuatan miniatur lampu rumah sebagai simulasi.

b. Pembuatan rangkaian kontrol lampu mikrokontroler Wemos D1 dengan komponen yang lain.

c. Pemasangan Web Browser aplikasi android.

d. Pembuatan software Arduino IDE operasi lampu mengunakan ESP8266.

\subsection{Langkah - langkah perakitan hardware}

Pada tahap ini dibutuhkan beberapa komponen agar alat dapat berjalan atau berfungsi dengan baik. Komponen yang dibutuhkan dalam pembuatan alat kendali lampu dengan wifi melalui aplikasi android berbasis mikrokontroler pada Tabel 1. dibawah ini.

Tabel 1. Daftar Komponen Rangkaian

\begin{tabular}{|c|r|c|}
\hline No & Komp & Fungsi \\
\hline 1 & Wemos D1 & $\begin{array}{c}\text { Sebagai Mikrokontroler untuk } \\
\text { memproses semua program }\end{array}$ \\
\hline
\end{tabular}

\begin{tabular}{|c|c|c|}
\hline 2 & ESP8266 & $\begin{array}{c}\text { Sebagai transfer data (IP } \\
\text { Address) dari Web Browser } \\
\text { aplikasi Smartphone ke } \\
\text { mikroknntroler }\end{array}$ \\
\hline 3 & Breadboard & $\begin{array}{c}\text { Sebagai tempat komponen } \\
\text { elektronika diletakkan dan } \\
\text { membuat ragkaian sementara }\end{array}$ \\
\hline 4 & Relai & $\begin{array}{c}\text { Berfungsi sebagai saklar } \\
\text { elektronik pada lampu }\end{array}$ \\
\hline 5 & $\begin{array}{c}\text { Smartphone } \\
\text { Android }\end{array}$ & $\begin{array}{c}\text { Untuk pemasangan Web Browser } \\
\text { aplikasi android dan memberikan } \\
I P \text { Address dari user }\end{array}$ \\
\hline
\end{tabular}

\subsection{Flowchart Arduino Wemos D1}

Flowchart Wemos D1 pada alat kontrol lampu dengan Wifi melalui aplikasi android berbasis mikrokontroler ditampilkan pada Gambar 3 . Flowchart kontrol lampu android berikut.



Gambar 3. Flowchart Arduino Wemos D1

\subsection{Pengoperasian Alat}

Pengoperasian alat ini dapat dilakukan dengan cara sebagai berikut:

a. Memastikan alat terhubung dengan tegangan 5 Volt untuk rangkaian mikrokontroler.

b. Menghubungkan wifi di android dengan ESP8266.

c. Memasukan IP Address untuk on/off lampu mengunakan Web Browser aplikasi Android yang telah terisntal di handphone.

\subsection{Pengujian Alat}

Pengujian alat dilakukan untuk mendapatkan data penelitian. Dalam pengujian alat ini dilakukan dengan dua pengujian, yaitu: 


\subsubsection{Uji Statis}

Pengujian dilakukan dengan cara menguji setiap bagian alat berdasarkan karakteristik dan fungsi masing-masing komponen. Pengujian dilakukan untuk mengetahui apakah setiap bagian dari perangkat telah bekerja sesuai dengan fungsinya.

\subsubsection{Uji Dinamis}

Pengujian unjuk kerja alat dilakukan dengan cara mengoperasikan alat dengan cara IP Address untuk mengoperasikan on/off lampu. Hal-hal yang perlu diamati adalah aplikasi android untuk menegtahui kinerja dari alat yang dibuat.

\subsection{Alur Penelitian}

Tahap penelitian pada alat kendali lampu dengan wifi melalui aplikasi android berbasis mikrokontroler dapat dilihat pada Gambar 4. Diagram Alur Penelitian Proses penelitian dilakukan melalui beberapa tahap sebagai berikut:

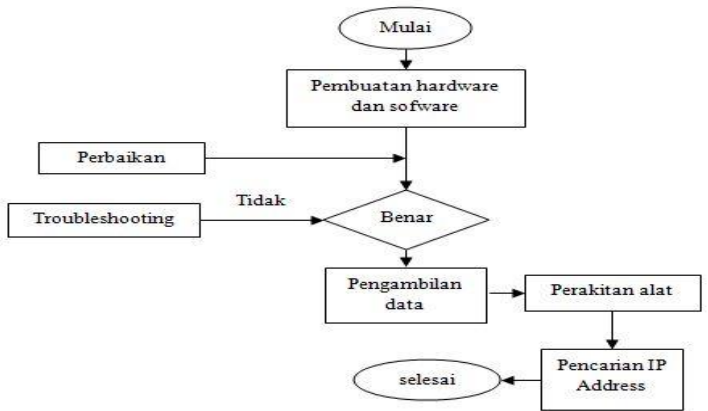

Gambar 4.. Alur Penelitian Alat Kontrol Lampu Dengan Wifi Melalui Web Browser Aplikasi

Android Berbasis Mikrokontroler

\section{PEMBAHASAN}

\subsection{Hasil Penelitian}

Alat rancang bangun pengoperasian lampu berbasis mikrokontroler terdiri dari dua bagian yaitu hardware dan software.

\subsubsection{Perangkat Keras Alat Rancang Bangun Pengoperasian Lampu \\ Perangkat keras alat rancang bangun pengoperasian lampu terdiri dari:
a. Arduino Wemos D1
b. ESP8266
c. Relai
d. Breadboard
e. Smartphone Android

Pengujian alat dilakukan menggunakan prototype lampu rumah untuk mengetahui apakah perancangan hardware dapat berjalan baik dengan prototype lampu rumah dan Web Browser aplikasi android yang telah terpasang. Pada pengujian ini Esp8266 akan melakukan pengiriman data sesuai perintah data yang dikirimkan dari Smartphone. Pada prototype lampu rumah ini nantinya akan mengoperasikan ESP8266 sehingga lampu rumah dapat hidup atau mati (lock). Perangkat Kendali lampu Dengan ESP8266 Melalui Aplikasi Android Berbasis Mikrokontroller dapat dilihat pada Gambar 5.

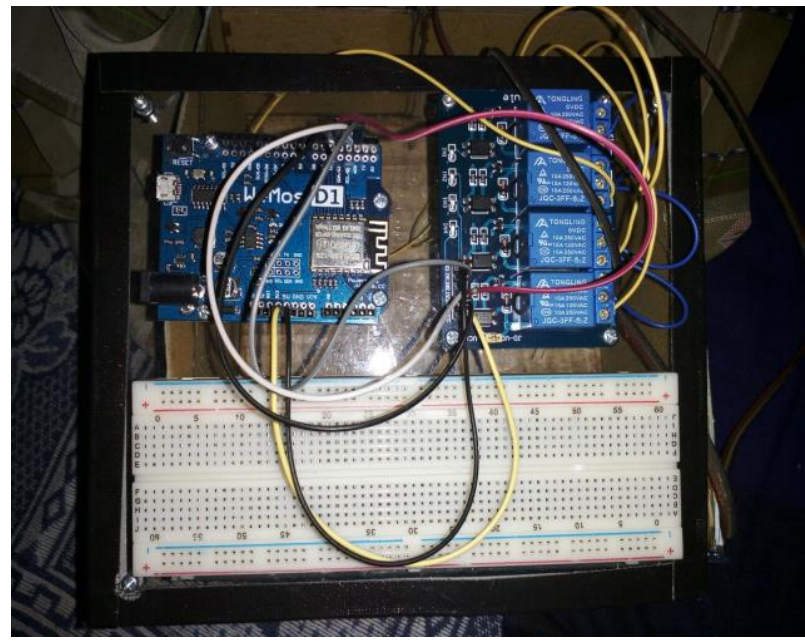

Gambar 5. Alat Rancang Bangun Pengoperasian lampu

Mikrokontroller Arduino Wemos D1 berfungsi untuk menngendalikan input atau output pada alat rancang bangun lampu. Semua rangkaian dapat dilihat pada Gambar 6.

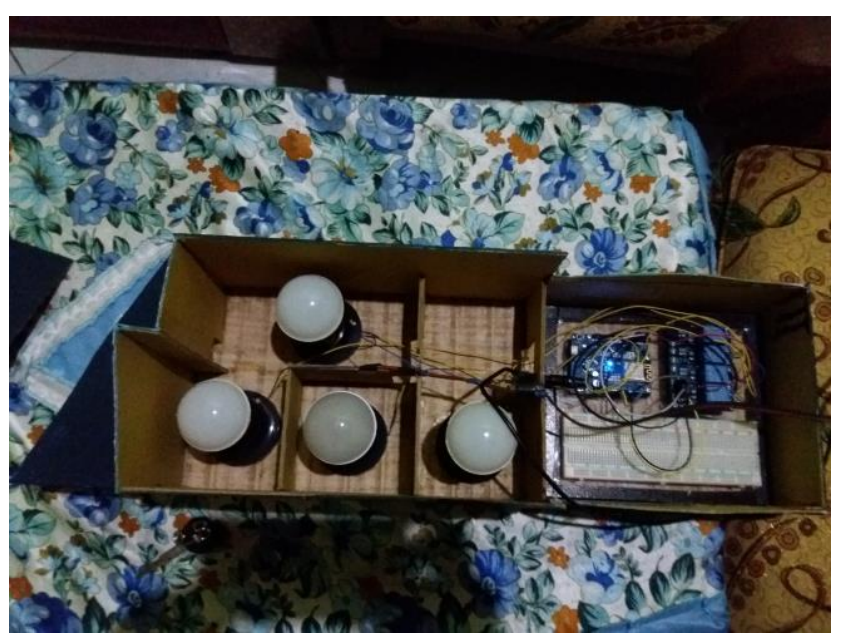

Gambar 6. Rangkaian Keseluruhan Kendali lampu dengan ESP8266 Melalui Web Browser Aplikasi Android Berbasis Mikrokontroller 


\subsubsection{Perangkat Lunak (Software)}

Software yang digunakan pada alat rancang bangun lampu adalah software arduino IDE berfungsi untuk memasukkan program pada Mikrokontroler Arduino Wemos D1. Sebagaimana dapat dilihat pada Gambar 7.

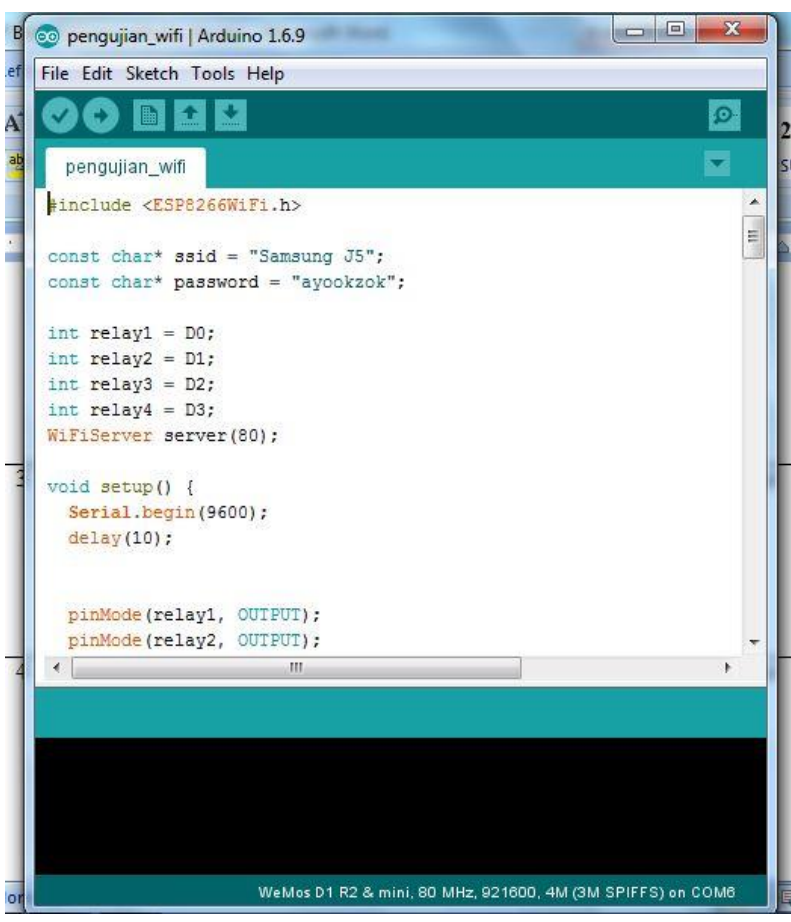

Gambar 7. Software Arduino IDE Pada Alat Rancang Bangun Pengoperasian Lampu Android

\subsection{Pengujian Mikrokontroler Arduino} Wemos D1

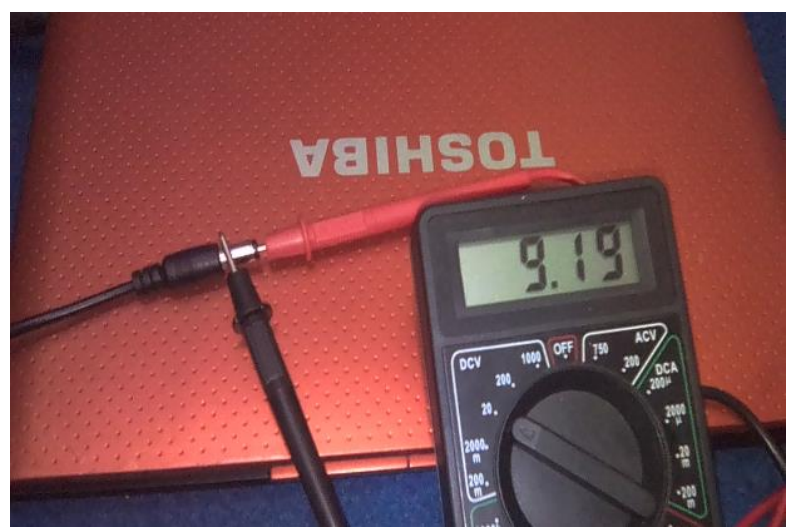

Tabel 2. Uji coba jarak ESP8266

\begin{tabular}{|c|c|c|}
\hline No & Jarak & Keterangan \\
\hline 1. & 10 meter & Memerima perintah \\
\hline 2. & 20 meter & Memerima perintah \\
\hline 3. & 30 meter & Memerima perintah \\
\hline 4. & 40 meter & Memerima perintah \\
\hline 5. & 50 meter & Memerima perintah \\
\hline 6. & 60 meter & Memerima perintah \\
\hline 7. & 70 meter & Memerima perintah \\
\hline 8. & 80 meter & Koneksi terputus \\
\hline
\end{tabular}

\subsection{Pelaksanaan Pengujian Pada Perangkat}

Gambar 8. Pengukuran Tegangan Power Suplly $9 \mathrm{v}$ 


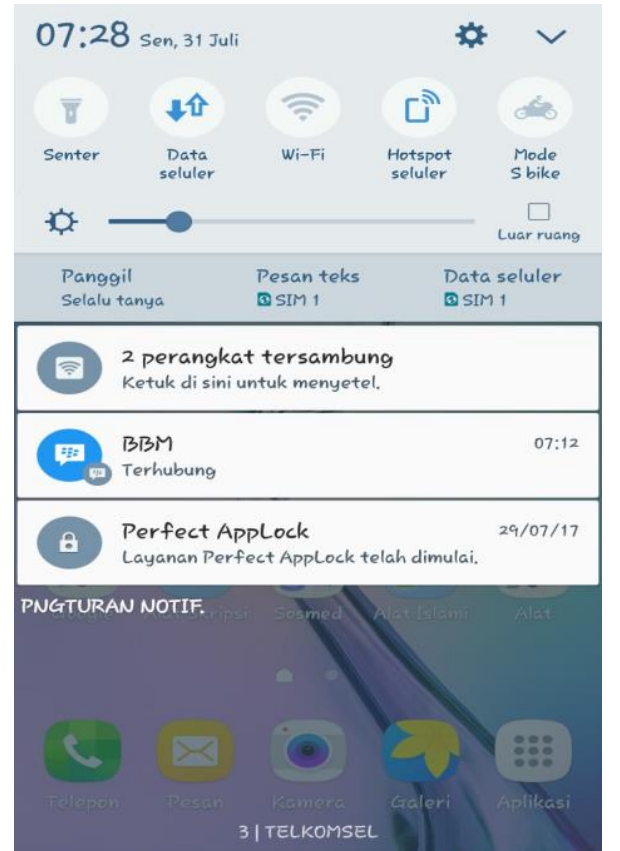

Gambar 10. Pengujian Koneksi Wifi Pada Alat Dengan Smartphone

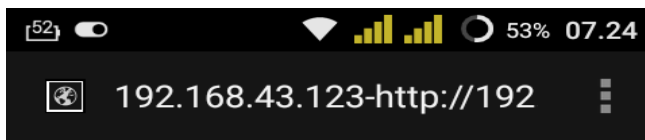

relay is now:

Click here turn the relay 1 on pin DO ON Click here turn the relay 1 on pin DO OFF Click here turn the relay2 on pin D1 ON Click here turn the relay2 on pin D1 OFF Click here turn the relay3 on pin D2 ON Click here turn the relay3 on pin D2 OFF Click here turn the relay4 on pin D3 ON Click here turn the relay4 on pin D3 OFF

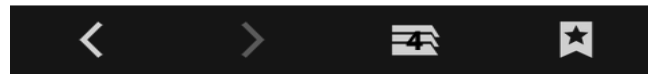

Gambar 11. Pengujian Ip Address Pada Web Browser Aplikasi Android

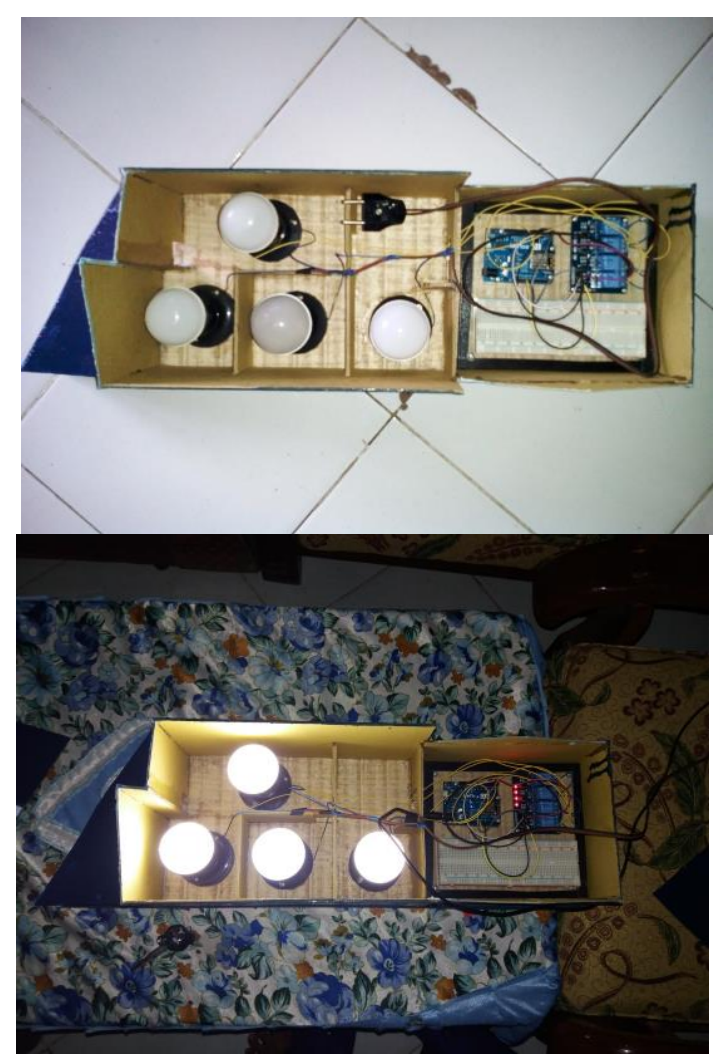

Gambar 12. Pengoperasian On/Off Lampu

\section{KESIMPULAN}

Berdasarkan pengukuran dan pengujian sistem, alat ini memiliki kelebihan yaitu:

1. Memiliki fitur untuk menghubungkan smartphone Android melalui koneksi Wifi untuk menghidupkan dan mematikan lampu menggunakan Android.

2. Hardware dan software telah berfungsi dengan baik, terbukti dengan alat yang mampu beroperasi sesuai dengan program dan perintah yang dimasukkan. Dan lampu mampu dikendalikan dengan jarak jauh $\underline{ \pm}$ 100 meter.

3. Dari sisi saklar sendiri lebih mudah di bawa di bandingkan saklar konvensional karena menggunakan smartphone sebagai saklar yang bisa dibawa kemana-mana tanpa harus menggunakan banyak saklar, dan Menjadikan smartphone android sebagai kontrol lampu untuk memberikan kenyamanan/keamanan dan mempermudah kebutuhan sehari-hari.

4. Alat prototype ini dapat melakukan pengontrolan lampu-lampu sesuai pengguna dalam mengendalikannya. 


\section{DAFTAR PUSTAKA}

[1]. Galih Rakasiwi. 2014: prototype pengontrolan lampu dengan android berbasis arduino via wifi. Surakarta: Tugas Akhir Universitas Muhammadiyah Surakarta.

[2]. Berita, 2017: http://radartegal.com/beritalokal/saklar-rusak-panti-asuhan-putera$\underline{\text { ludes-terbakar,13748.html }}$

[3]. Vcc2GND. 2014: http://www.vcc2gnd.com/sku/ESP8266

[4]. Indrajid. 2000. Analisis dan perancangan system Berorientasi Object. Bandung. Informatika

[5]. Sinauarduino, 2016: http://www.sinauarduino.com/artikel/categ ory/modul/

Tresna widiyaman, 2016: http://www.warriomux.com/pengertianmodul-wifi-esp8266/

[6]. Irawan, 2012: Membuat Aplikasi Android Untuk Orang Awam. Palembang: Maxikom.

[7]. Dian mustiya putri \& Eko rudiawan, 2017. Mengenal wemos d1 mini dalam dunia IoT.

https://dianmustikaputri.wordpress.com

[8]. Nyoman yudi, \& Rani K. 2011: http://www.aisi555.com/2011/07/mengena l-project-board-atau-bread boad.html?m=1

[9] Dickson Kho, Admin. 2016: Pengertian, fungsi dan cara kerja relay. http://belajarelektronik.net/pengertianfungsi-dan-cara-kerja-relay/

[10]. Syahwil, M. 2013. Panduan mudah simulasi dan praktek mikrokontroler arduino. Edisi pertama. Andi offset. Yogyakarta.

[11] Sugiyono, 2012: Metode Penelitian Kuantitatif, Kualitatif, Dan R\&D Cetakan Ke 1, Alfabeta, Bandung. 